\title{
Prediction of Prolonged Pregnancy in Nulliparous Women by Transvaginal Ultrasonographic Measurement of Cervical Length at 20-24 Weeks and 37 Weeks
}

\begin{abstract}
This study was done to evaluate transvaginal ultrasonographic measurement of cervical length at 20 to 24 weeks and 37 weeks as a predictor of prolonged pregnancy (defined as a pregnancy that extended beyond $41+2$ weeks of gestation [289 days]) in nulliparous women. This prospective observational study enrolled 149 consecutive nulliparous women with singleton gestation at 37 weeks. Cervical length was measured by transvaginal ultrasonography at 20 to 24 weeks and 37 weeks. Cervical length at 37 weeks, but not at 20 to 24 weeks, was significantly longer in women delivered at $>41+2$ weeks than in those delivered at $\leq 41+2$ weeks $(p<0.005)$. There was a significant correlation between cervical length at 37 weeks and gestational age at delivery (Pearson correlation coefficient, $r=0.387, p<0.0001$ ). In the receiver operating curve, the best cut-off value of cervical length at 37 weeks for the prediction of prolonged pregnancy was $30 \mathrm{~mm}$, with a sensitivity of $78 \%$ and a specificity of $62 \%$. Cervical length assessed by transvaginal ultrasonography at 37 weeks can predict the likelihood of prolonged pregnancy in nulliparous women. However, there is no association between cervical length at 20 to 24 weeks and the occurrence of prolonged pregnancy.
\end{abstract}

Key Words : Pregnancy, Prolonged; 37-week Scan; Cervix Uteri; Cervical Length; Primiparity; Parity

\begin{abstract}
Young Hoon Suh, Kyo Hoon Park, Joon-Seok Hong, Jae Hong Noh
\end{abstract}

Department of Obstetrics and Gynecology, Seoul National University Bundang Hospital, Seongnam, Korea

Received : 2 August 2006

Accepted : 21 November 2006

Address for correspondence

Kyo Hoon Park, M.D.

Department of Obstetrics and Gynecology, Seoul National University Bundang Hospital, 300

Gumi-dong, Bundang-gu, Seongnam 463-707, Korea

Tel : +82.31-787-7252, Fax : +82.31-787-4054

E-mail : pkh0419@snubh.org

\section{INTRODUCTION}

Prolonged pregnancy occurs in approximately $10 \%$ of all singleton pregnancies and is associated with an increased risk of fetal macrosomia, intrapartum fetal heart abnormalities, meconium staining, perinatal death, and cesarean delivery (1-3). An early prediction of this condition is important because several methods to decrease the rate of prolonged pregnancy, such as membrane stripping and outpatient prostaglandin therapy, have been already proposed $(4,5)$. Therefore there has been considerable interest in the development of tests for the prediction of prolonged pregnancy. These tests include fetal fibronectin, cytokine, or nitric oxide concentrations in cervicovaginal secretions and cervical length as determined by ultrasonography (6-10).

Cervical length measured by transvaginal ultrasound in the second trimester has been well known to be effective in identifying pregnancies at high-risk of spontaneous preterm delivery (11-16). Recent studies have reported that sonographic measurement of cervical length at term is a useful predictor of the likelihood of successful induction of labor and the spontaneous onset of labor in a 7-day period (17-21). Moreover, Romero et al. have proposed that cervical ripen- ing is part of the common terminal pathway of human parturition, which includes uterine contractility and membranedecidua activation (22). These observations suggest that a passively shortened or dilated cervix may play a role in the mechanisms responsible for the initiation of parturition (preterm and term). Therefore if the shorter the cervix, the greater the risk of preterm delivery, the likelihood of successful induction of labor and the spontaneous onset of labor, it is possible that a longer cervix may predict a higher risk of prolonged pregnancy. The purpose of this study was to determine whether the transvaginal ultrasonographic measurement of cervical length at 20 to 24 weeks and 37 weeks can predict prolonged pregnancy in nulliparous women.

\section{MATERIALS AND METHODS}

\section{Study design}

This was a prospective observational study conducted at Seoul National University Bundang Hospital (Seongnam, Korea) between June 2004 and May 2006. Women attending the antenatal clinic were enrolled at 37 weeks. In our 
institution ultrasound examination is carried out routinely at 11-14 weeks and at 20-24 weeks of gestation. The scan at 20-24 weeks included fetal examination and the option of having a transvaginal scan to measure cervical length as a screening test for spontaneous preterm delivery. The inclusion criteria were: 1) nulliparous women; 2) singleton pregnancy; 3) live fetus with vertex presentation; 4) intact amniotic membranes; 5) known gestational age confirmed by ultrasound measurement of crown-rump length $(\mathrm{CRL})$ (gestational age was corrected on the basis of CRL measurement if a discrepancy of 7 days or more exists); 6) with sonographically measured cervical length between 20 and 24 weeks; 7) no pregnancy complications (i.e., fetal growth restriction, preeclampsia, and major fetal abnormalities); 8) absence of labor; 9) no history of previous uterine surgery. Prolonged pregnancy was defined as a pregnancy that extended beyond 41 weeks and 2 days (289 days) (this definition was developed because we usually induced labor in patients who did not go into spontaneous onset of labor by that date). Week of gestation was defined as completed week; i.e., week 37 refers to 37.0 weeks to 37.6 weeks menstrual age. The results of the ultrasound were blinded for the clinicians. This study was approved by the institutional review board of our institution Seoul National University Bundang Hospital. Informed consent was obtained prior to enrollment in the study.

\section{Transvaginal ultrasound of the cervix}

Transvaginal ultrasonographic assessment of the cervical length was performed by one of the authors at 20-24 weeks using an Aloka SSD 5500 (Aloka Co. Ltd, Tokyo, Japan) ultra-

Table 1. Clinical characteristics and obstetric outcomes in women going beyond term and those with spontaneous term delivery

\begin{tabular}{lccc}
\hline & $\begin{array}{c}\text { Post-term delivery } \\
(\mathrm{n}=23)\end{array}$ & $\begin{array}{c}\text { Term delivery } \\
(\mathrm{n}=126)\end{array}$ & $\begin{array}{c}p \\
\text { values }\end{array}$ \\
\hline $\begin{array}{l}\text { Maternal age (yr) } \\
\text { Gestational age at } \\
\text { delivery (weeks) }\end{array}$ & $31.0 \pm 5.2$ & $29.9 \pm 3.3$ & NS \\
$\begin{array}{c}\text { Cervical length at 20-24 } \\
\text { weeks (mm) }\end{array}$ & $40.9 \pm 5.5$ & $39.1 \pm 5.5$ & NS \\
$\begin{array}{c}\text { Gestational age at ultraso- } \\
\text { nographic examination of } \\
\text { cervical length measured }\end{array}$ & $21.3 \pm 1.1$ & $21.7 \pm 1.1$ & NS \\
$\begin{array}{l}\text { between 20 and 24 weeks } \\
\text { (weeks) }\end{array}$ & & & \\
$\begin{array}{c}\text { Cervical length at 37 weeks } \\
\text { (mm) }\end{array}$ & $31.9 \pm 6.4$ & $27.7 \pm 6.4$ & $<0.005$ \\
$\begin{array}{l}\text { Birth weight (g) } \\
\text { Mode of labor onset }\end{array}$ & $3,620 \pm 406$ & $3,264 \pm 312$ & $<0.001$ \\
$\begin{array}{l}\text { Spontaneous } \\
\text { Induced }\end{array}$ & $13 \%(3 / 23)$ & $100 \%(126 / 126)$ & \\
Cesarean delivery & $87 \%(20 / 23)$ & & \\
\hline
\end{tabular}

Values are given as mean $\pm S D$ or percent (n). NS, Not significant. sound machine with a $6.0 \mathrm{MHz}$ transducer and at 37 weeks using an Envisor (Philips Medical System, Netherlands) ultrasound machine with a $6.0 \mathrm{MHz}$ transducer. Women were asked to empty their bladder and were placed in the dorsal lithotomy position. The probe was gently placed at the anterior fornix of the vagina to obtain a sagittal view of the complete cervix, including the internal os, external os, and endocervical canal. The probe was slowly withdrawn until the image blurred and then the insertion pressure was increased only enough to restore a clear cervical image. This cervical image was magnified to at least $75 \%$ of the screen and the electronic markers were placed at the furthest points between the internal os and external os, then cervical length was measured as a straight line. The shortest of three measurement obtained was taken as the cervical length.

\section{Statistical analysis}

Univariate analysis was conducted using the Mann-Whitney $U$ test or the $\chi^{2}$ test. Receiver operating characteristic (ROC) curves were constructed to describe the relationship between the sensitivity (true-positive rate) and the false-positive rate for the cervical length in predicting prolonged pregnancy. Pearson correlation analysis was used to determine the relationship between sonographically measured cervical length and gestational age at delivery. $p$ values of $<0.05$ were considered statistically significant.

\section{RESULTS}

During the study period, 184 consecutive women met the inclusion criteria in this study. Of these, 35 women had labor induced before 41 weeks and 2 days because of oligohydramnios $(n=28)$, non-reassuring non-stress test $(n=3)$, and request for social reason $(n=4)$. Thus, these women were excluded from the study, leaving a total of 149 women qualified for inclusion. Spontaneous onset of labor and delivery at or before 41 weeks and 2 days occurred in $126(85 \%)$ women. In 23 women $(15 \%)$ that remained undelivered beyond 41 weeks and 2 days, 20 had induction of labor and 3 had spontaneous onset of labor. Cervical length was successfully measured in all cases and the mean ( \pm standard deviation) cervical lengths at 20 to 24 weeks and 37 weeks were $39 \pm 6 \mathrm{~mm}$ and $28 \pm$ $6 \mathrm{~mm}$, respectively.

Table 1 presents the clinical characteristics and obstetric outcomes of patients according to the study group. No significant differences were found in terms of median maternal age and median gestational age at ultrasound examination of cervical length measured between 20 and 24 weeks between the study groups. However, women going beyond term had a significantly higher rate of cesarean delivery and greater mean birth weight than did those with spontaneous term delivery. Moreover, the median cervical length at 37 weeks 


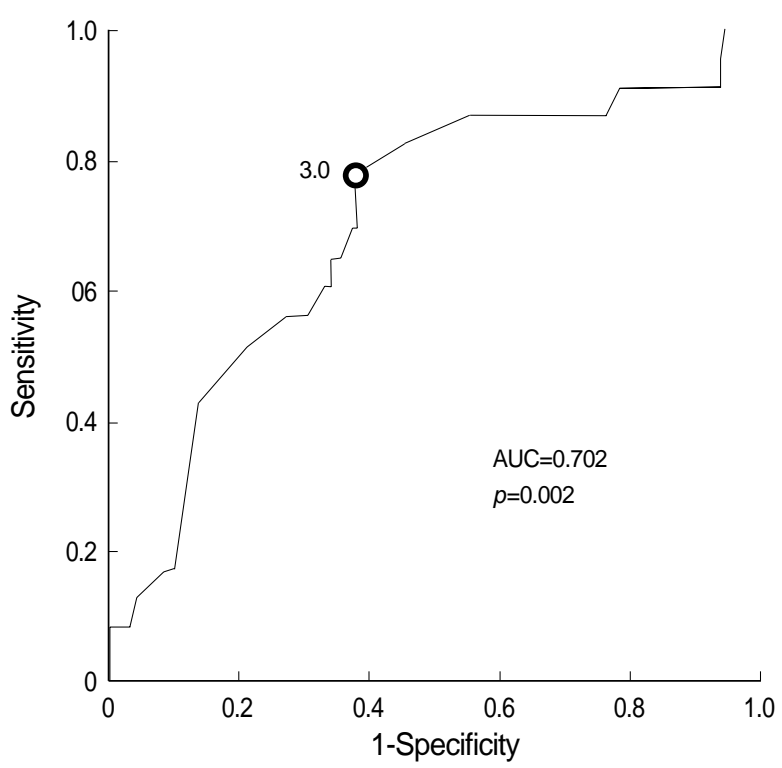

Fig. 1. Receiver operating characteristic curve analysis for sonographically measured cervical length at 37 weeks in predicting prolonged pregnancy. Number next to solid dot represents cervical length $(\mathrm{mm})$ at 37 weeks (area under the curve 0.702, SE $0.060, p<0.005)$.

was significantly longer in women going beyond term than in those with spontaneous term delivery, but the median cervical length at 20-24 weeks were not significantly different between the two study groups.

Fig. 1 displays the ROC curve for sonographically measured cervical length at 37 weeks in predicting prolonged pregnancy. The curve constructed for sonographically measured cervical length was above the $45^{\circ}$ line, indicating that there was a significant relationship between this variable and prolonged pregnancy (area under the curve 0.702; SE 0.060; $p<0.005)$. The best cut-off value for the prediction of prolonged pregnancy was $30 \mathrm{~mm}$ with a sensitivity of $78 \%$ and a specificity of $62 \%$. A significant positive correlation between sonographically measured cervical length at 37 weeks and gestational age at delivery was noted $(r=0.387, p<0.0001)$ (Fig. 2). However, there was no correlation between cervical length at 20-24 weeks and gestational age at delivery.

\section{DISCUSSION}

The results of our study clearly demonstrate that cervical length assessed by transvaginal ultrasonography at 37 weeks can predict the likelihood of prolonged pregnancy and is associated with the gestation at spontaneous onset of labor in low-risk nulliparous women. Furthermore, our data indicate that these associations did not exist as early as 20 to 24 weeks. Similar observations have been made in other gestational ages (i.e., at 11 to 14 weeks and 22 to 24 weeks of gestation) in the setting of spontaneous preterm delivery $(12,13)$.

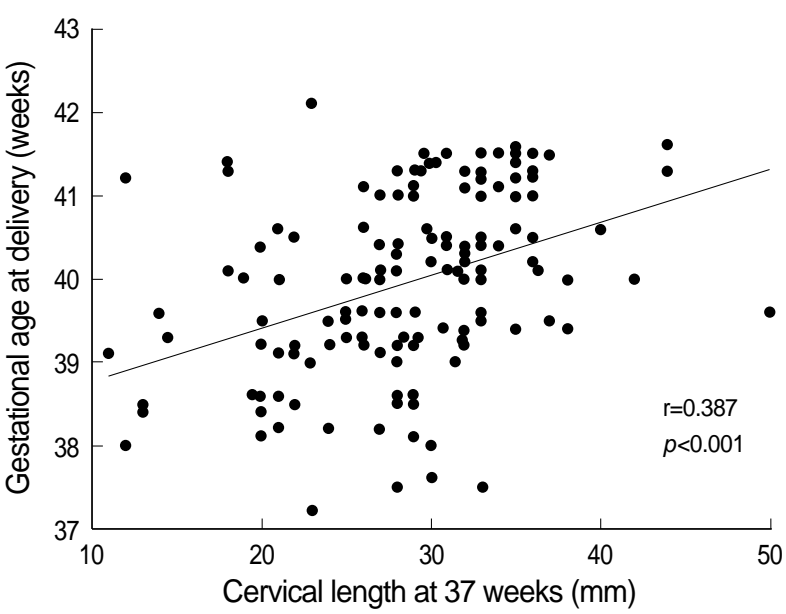

Fig. 2. Sonographically measured cervical length at 37 weeks and gestational age at delivery. There was a significant positive correlation between sonographically measured cervical length at 37 weeks and gestational age at delivery $(r=0.387, p<0.0001)$.

Several investigators have reported that measurement of cervical length in the second trimester provides accurate prediction of risk for spontaneous preterm delivery and this risk is inversely correlated with cervical length (11-16). However, there are few reports on cervical length in the second trimester of pregnancy in relation to prolonged pregnancy. Some studies have begun cervical assessment at 37 weeks and demonstrated that cervical length at 37 weeks is associated with the incidence of prolonged pregnancy and the spontaneous onset of labor in a 7-day period $(9,10,21)$. To our knowledge, this is the first report to examine the relationship between cervical length in the second trimester and the occurrence of prolonged pregnancy. The results are unexpected, in that relationship found in spontaneous preterm delivery does not exit (i.e., the longer the cervical length in the second trimester, the higher the rate of prolonged delivery). These findings imply that cervical assessment provide sensitive prediction of spontaneous delivery (preterm or term) within the next some weeks, not the next some months, regardless of whether this assessment is performed in the second trimester or at term.

A major finding in this study is that cervical length at 37 weeks can predict the likelihood of prolonged pregnancy. This finding is in keeping with the observation made by Ramanathan et al. who demonstrated that measurement of cervical length at 37 weeks can be used to determine the likelihood of prolonged pregnancy and the risk of cesarean section in those requiring induction for prolonged pregnancy (9). Conflicting finding, however, has been reported by Vimercati et al. (10). They demonstrated that the measurement of cervical length at 39 weeks and 40 weeks was significantly shorter in a group who had spontaneous onset of labor before 41 completed weeks of gestation than in that who did not, but the measurement of cervical length was similar in both group at 37 weeks and 38 weeks. The disparity among these studies is probably attributable to a combination of factors, 
including the definition of prolonged pregnancy, the study population to participate (i.e., nulliparity or primiparity), and sample size. Nulliparity was chosen as the enrollment criterion of our study because primiparity and prior prolonged pregnancy are the most common identifiable risk factor for prolongation of pregnancy $(9,23,24)$.

It is noteworthy that a significant positive correlation between cervical length at 37 weeks and gestational age at delivery was noted. This finding is consistent with the observations of Ramanathan et al. who documented a high association between cervical length at 37 weeks and gestation at spontaneous onset of labor (9). Moreover, in the current study, cervical length at 37 weeks $\geq 30 \mathrm{~mm}$ had a sensitivity of $78 \%$ and a specificity of $62 \%$ in the prediction of prolonged pregnancy. These data have several clinical implications for the management of patients at term. First, if routine measurement of cervical length at 37 weeks can identify patients at high risk of prolonged pregnancy, the incidence of prolonged pregnancy or the risks associated with prolonged pregnancy will be reduced because simple method to promote spontaneous onset of labor (i.e., membranes stripping and outpatient prostaglandin therapy) was already proposed $(4,5)$. Second, these data may be utilized in individualizing the timing of elective cesarean section rather than performance of this operation at 38 weeks. Third, from the patients' point of view these data may give patients information to arrange their social activities and to deal with their anxiety.

Our study has demonstrated that the mean cervical lengths at 20 to 24 weeks and 37 weeks are, respectively, $39 \mathrm{~mm}$ and $28 \mathrm{~mm}$ in singleton low-risk pregnancies delivered at or beyond term. These findings are similar to those of previous reports $(9,12,25)$. Moreover, our data indicated that the cervical length decreased from the second trimester to term and this spontaneous shortening was, however, more pronounced in women delivered at term than in those going beyond term. The mean cervical length in women delivered at term decreased from $39.1 \mathrm{~mm}$ to $27.7 \mathrm{~mm}$. On the other hand, in women going beyond term, the shortening of the cervix was from $40.9 \mathrm{~mm}$ to $31.9 \mathrm{~mm}$ between the 20-24-week and the 37-week evaluations. These findings indicate that the relatively slow rate of spontaneous cervical shortening between the second trimester and term pregnancy might be related to the occurrence of prolonged pregnancy. In a similar study, Vimercati et al. also reported that women who remained undelivered beyond 41 weeks has a delayed effacement process and the measurement of cervical length at 41 weeks in these women would possibly show the same pattern as that at 39 weeks in women who had spontaneous onset of labor before 41 weeks (10). On the other hand, in the context of spontaneous preterm delivery, Carvalho et al. have found that there is a spontaneous shortening in the pregnant cervix from the first to the second trimester of pregnancy and this shortening is more rapid in pregnant women who deliver prematurely (12).
A limitation of the current study is that cervical length was measured as a straight line because from the practical point of view, it is reasonable to measure the linear distance between the internal and external os. Although in cases with a curved cervix the longer the measurement taken along the endocervical canal, the longer inevitably the measurement of cervical length taken as a straight line, cervical length in our study population, especially measured at 20-24 weeks, may not represent true cervical length.

In conclusion, cervical length at 37 weeks can predict the likelihood of prolonged pregnancy and is associated with the gestation at spontaneous onset of labor in low-risk nulliparous women. However, cervical length at 20 to 24 weeks is associated with neither prolonged delivery nor the gestation at spontaneous onset of labor.

\section{REFERENCES}

1. Rand L, Robinson JN, Economy KE, Norwitz ER. Post-term induction of labor revisited. Obstet Gynecol 2000; 96: 779-83.

2. Sanchez-Ramos L, Olivier F, Delke I, Kaunitz AM. Labor induction versus expectant management for postterm pregnancies: a systematic review with meta-analysis. Obstet Gynecol 2003; 101: 1312-8.

3. ACOG Practice Bulletin. Clinical management guidelines for obstetricians-gynecologists. Number 55, September 2004 (replaces practice pattern number 6, October 1997). Management of Postterm Pregnancy. Obstet Gynecol 2004; 104: 639-46.

4. Magann EF, McNamara MF, Whitworth NS, Chauhan SP, Thorpe RA, Morrison JC. Can we decrease postdatism in women with an unfavorable cervix and a negative fetal fibronectin test result at term by serial membrane sweeping? Am J Obstet Gynecol 1998; 179: 890-4.

5. McKenna DS, Costa SW, Samuels P. Prostaglandin E2 cervical ripening without subsequent induction of labor. Obstet Gynecol 1999; 94: 11-4.

6. Imai M, Tani A, Saito M, Saito K, Amano K, Nisijima M. Significance of fetal fibronectin and cytokine measurement in the cervicovaginal secretions of women at term in predicting term labor and postterm pregnancy. Eur J Obstet Gynecol Reprod Biol 2001; 97: 53-8.

7. Lockwood CJ, Moscarelli RD, Wein R, Lynch L, Lapinski RH, Ghidini A. Low concentrations of vaginal fetal fibronectin as a predictor of deliveries occurring after 41 weeks. Am J Obstet Gynecol 1994; 171: 1-4.

8. Vaisanen-Tommiska M, Nuutila M, Ylikorkala O. Cervical nitric oxide release in women postterm. Obstet Gynecol 2004; 103: 657-62.

9. Ramanathan G, Yu C, Osei E, Nicolaides KH. Ultrasound examination at 37 weeks' gestation in the prediction of pregnancy outcome: the value of cervical assessment. Ultrasound Obstet Gynecol 2003; 22: 598-603.

10. Vimercati A, Greco P, Lopalco P, Loizzi V, Scioscia M, Mei L, Rossi $\mathrm{AC}$, Selvaggi $\mathrm{L}$. The value of ultrasonographic examination of the uterine cervix in predicting post-term pregnancy. J Perinat Med 2001; 29: $317-21$.

11. Iams JD, Goldenberg RL, Meis PJ, Mercer BM, Moawad A, Das A, 
Thom E, McNellis D, Copper RL, Johnson F, Roberts JM. The length of the cervix and the risk of spontaneous premature delivery. National Institute of Child Health and Human Development Maternal Fetal Medicine Unit Network. N Engl J Med 1996; 334: 567-72.

12. Carvalho MH, Bittar RE, Brizot ML, Maganha PP, Borges da Fonseca ES, Zugaib M. Cervical length at 11-14 weeks' and 22-24 weeks' gestation evaluated by transvaginal sonography, and gestational age at delivery. Ultrasound Obstet Gynecol 2003; 21: 135-9.

13. Hassan SS, Romero R, Berry SM, Dang K, Blackwell SC, Treadwell MC, Wolfe HM. Patients with an ultrasonographic cervical length < or $=15 \mathrm{~mm}$ have nearly a 50\% risk of early spontaneous preterm delivery. Am J Obstet Gynecol 2000; 182: 1458-67.

14. Murakawa H, Utumi T, Hasegawa I, Tanaka K, Fuzimori R. Evaluation of threatened preterm delivery by transvaginal ultrasonographic measurement of cervical length. Obstet Gynecol 1993; 82: 829-32.

15. Heath VC, Southall TR, Souka AP, Elisseou A, Nicolaides KH. Cervical length at 23 weeks of gestation: prediction of spontaneous preterm delivery. Ultrasound Obstet Gynecol 1998; 12: 312-7.

16. To MS, Skentou C, Liao AW, Cacho A, Nicolaides KH. Cervical length and funneling at 23 weeks of gestation in the prediction of spontaneous early preterm delivery. Ultrasound Obstet Gynecol 2001; 18: 200-3.

17. Ware V, Raynor BD. Transvaginal ultrasonographic cervical measurement as a predictor of successful labor induction. Am J Obstet Gynecol 2000; 182: 1030-2.

18. Gabriel R, Darnaud T, Chalot F, Gonzalez N, Leymarie F, Quereux
C. Transvaginal sonography of the uterine cervix prior to labor induction. Ultrasound Obstet Gynecol 2002; 19: 254-7.

19. Pandis GK, Papageorghiou AT, Ramanathan VG, Thompson MO, Nicolaides KH. Preinduction sonographic measurement of cervical length in the prediction of successful induction of labor. Ultrasound Obstet Gynecol 2001; 18: 623-8.

20. Rane SM, Pandis GK, Guirgis RR, Higgins B, Nicolaides KH. Preinduction sonographic measurement of cervical length in prolonged pregnancy: the effect of parity in the prediction of induction-to-delivery interval. Ultrasound Obstet Gynecol 2003; 22: 40-4.

21. Rozenberg P, Goffinet F, Hessabi M. Comparison of the Bishop score, ultrasonographically measured cervical length, and fetal fibronectin assay in predicting time until delivery and type of delivery at term. Am J Obstet Gynecol 2000; 182: 108-13.

22. Romero R, Gomez R, Mazor M, Ghezzi F, Yoon BH. The preterm labor syndrome. In: Elder MG, Lamont RF, Romero R, editors, Preterm labor. New York: Churchill Livingstone, 1997; xii, 553 p.

23. Alfirevic Z, Walkinshaw SA. Management of post-term pregnancy: to induce or not? Br J Hosp Med 1994; 52: 218-21.

24. Mogren I, Stenlund H, Hogberg U. Recurrence of prolonged pregnancy. Int J Epidemiol 1999; 28: 253-7.

25. Brieger GM, Ning XH, Dawkins RR, Ying KQ, Weng C, Chang AM, Haines CJ. Transvaginal sonographic assessment of cervical dynamics during the third trimester of normal pregnancy. Acta Obstet Gynecol Scand 1997; 76: 118-22. 